\title{
Rainy season characteristics of the Free State Province of South Africa with reference to rain-fed maize production
}

\author{
ME Moeletsij ${ }^{1,2 *}$ and S Walker ${ }^{2}$ \\ ${ }^{1}$ Agricultural Research Council - Institute for Soil, Climate and Water, Private Bag X79, Pretoria 0001, South Africa \\ ${ }^{2}$ Department of Soil, Crop and Climate Sciences, University of the Free State, PO Box 339, Bloemfontein 9300, South Africa
}

\begin{abstract}
The study assesses onset of rains, cessation of rains, duration of rainy season and seasonal rainfall at different probability levels. Daily rainfall data for 309 stations located in the Free State Province of South Africa were analysed from 1950 to 2008. The cumulative rainfall over 3 consecutive dekads (10-day periods) and cumulative rainfall over 1 dekad were used to determine onset of rains and cessation of rains respectively. Seasonal rainfall was determined as the accumulated rainfall from November to March. Rainbow statistical software was utilised to test for normality and determine probabilities at $20 \%, 50 \%$ and $80 \%$ risk levels. The other rainy season characteristics investigated were the probability of onset failure and probability of rainy season duration of less than 50,100,120 and 140 days. These rainy season indices were investigated in relation to maize production in the Free State. Rainfall behaviour during the growing period is one of the main limiting factors to rain-fed maize production, consequently influencing household food security. The results show that for onset of rains there is a large spatial variance over the Free State while cessation of rains shows small variance. There is also an east to west progression of onsets while the duration of the rainy season and seasonal rainfall also increased from west to east. Areas of low risk associated with rainy season characteristics are evident over the Thabo Mofutsanyane, eastern Motheo, eastern and northeastern Lejweleputswa and the Fezile Dabi districts, making these areas highly suitable for maize production. By contrast, high-risk areas are in the western and southern parts of the province and thus dryland maize production has low production potential in these areas.
\end{abstract}

Keywords: onset of rains, cessation of rains, seasonal rainfall

\section{Introduction}

Rainfall is one of the weather elements which varies greatly on a spatial and temporal basis, impacting on agricultural activities (Mwale et al., 2004; Tveito et al., 2005; Moeletsi et al., 2011b). According to Sivakumar (1990) and Mugulavai et al. (2008), it is important to determine at a reasonable accuracy the probability levels of the onset of rains, cessation of rains and length of rainy period, as well as their inter-relationships, in order to assist in planning of dryland farming activities. Knowledge of the length and probable dates of the onset and cessation of the rainy season can help farmers choose the right cultivar suitable for their particular location or region (Tadross et al., 2005). Research in other parts of the world has shown that farmers are interested in obtaining the dates on which they can start planting, knowing that the likelihood of crop failure is then minimal (Ati et al., 2002).

During spring, farmers are always anticipating the coming of the first rains in order for them to make preparations for the growing season. Onset of rainfall is one of the most important occurrences to the farmer: earlier onset allows them to plough land and plant earlier and benefit from the lower evaporative demand, while later onset can cause the plant critical stages that are sensitive to water stress to be aligned with months of lower rainfall and higher evaporative demand, depending on location and timing of the onset of rains (Moeletsi et al., 2011a).

* To whom all correspondence should be addressed.

욜

+27 12310 2537; fax: +27 12323 1157;

e-mail: moeletsim@arc.agric.za; mmoeletsi@hotmail.com

Received 20 January 2011; accepted in revised form 3 October 2012.
If the farmer is able to time planting in such a way as to avoid false onset of rains and the plants' crop water requirements are met at critical stages of development then that season's productivity will be increased. The determination of the cessation of rains is as important as the onset because this will enable proper determination of the length of the rainy season and thus enable decision makers to make suitable choices of the type of crop or cultivar to plant for that particular location. In semiarid areas like the Free State it is impossible to ensure high skill in forecasting of planting dates, but, when agrometeorological information about the behaviour of the rainy season is available, crop losses should be minimised (Sivakumar, 1990; Raes et al., 2004). As with most semi-arid areas, the Free State Province's agricultural production is affected by high climate variability which causes the dates for the onset and cessation of rains, length of the rainy season and seasonal rainfall to be highly uncertain (Camberlin and Diop, 2003; Usman and Reason, 2004; Mugulavai et al., 2008).

It has to be noted that most southern African economies are dependent on rainfed agriculture and thus unfavourable weather conditions result in low economic performance and high food insecurity, while seasons that are characterised by favourable weather conditions for crop production result in widespread economic recovery (Unganai, 1994; Tsheko, 2003). Agricultural losses in southern Africa are mainly caused by climate variability impacting mostly the resource-poor farmers, whose livelihoods depend solely on agriculture (Tadross et al., 2005). Rural areas are the most vulnerable places and should be given priority in cases of food relief or any other social assistance that is required after the occurrence of extreme weather conditions that have adversely affected agricultural productivity (Vogel and Drummond, 1993; Reason et al., 2005). 


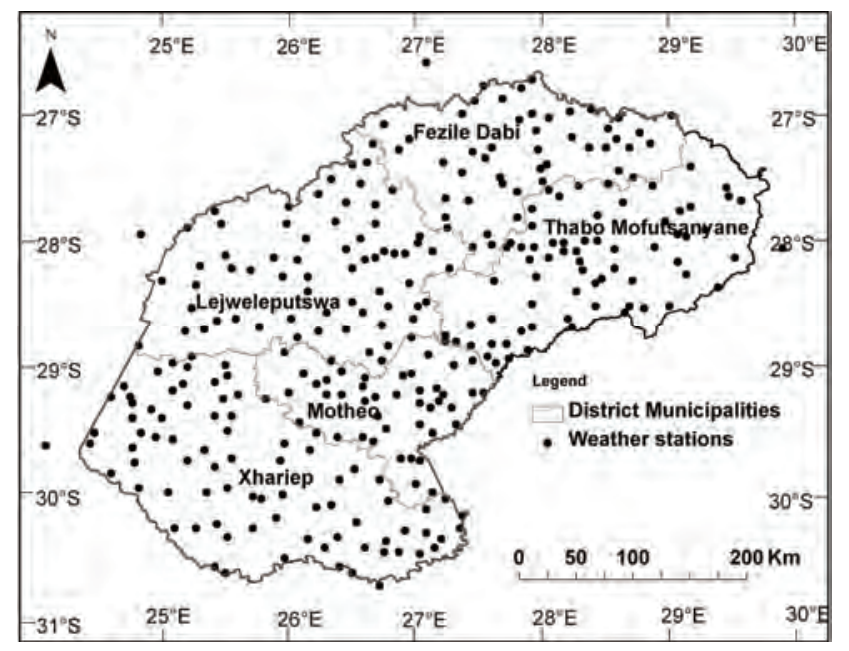

Figure 1

Distribution of rainfall stations used in the analysis of rainy season characteristics over the Free State Province

In this study, the rainy season characteristics over the Free State Province were investigated. The risk or probability levels of onset, cessation and duration of the rainy season were determined, as well as the seasonal rainfall, and probabilities of onset failure and a rainy season of less than a specific duration. The study was initiated because of the high variability that is associated with the rainfall season characteristics for dryland maize production in the Free State.

\section{Methodology}

\section{Study area}

The Free State Province is situated between latitudes $26.6^{\circ} \mathrm{S}$ and $30.7^{\circ} \mathrm{S}$ and between longitudes $24.3^{\circ} \mathrm{E}$ and $29.8^{\circ} \mathrm{E}$. It is South Africa's third-largest province with an area of around 129825 $\mathrm{km}^{2}, 10.6 \%$ of the country's land area (FSP, 2005; Davis et al., 2006). The province is administratively divided into 5 municipal districts (Fig. 1) (Davis et al., 2006): Fezile Dabi, Lejweleputswa, Motheo, Thabo Mofutsanyane and Xhariep. The main economic activities contributing significantly towards the gross domestic product of the province are community service (24.7\%), agriculture (20.1\%), trade (10.7\%) and mining (9.6\%) (FSP, 2005). The Free State Province contributes significantly to the agricultural economy of the country with an average of $3 \mathrm{~m}$. tons of maize a year, comprising over $30 \%$ of the national maize production (De Jager et al., 1998; DAFF, 2010). Agriculture in the province is mostly rain-fed with less than $10 \%$ of the arable land being under irrigation. This, together with high climate variability associated with rainfall onset, cessation and duration of rainy season, emphasises the importance of studies of rainy season behaviour in the Free State Province.

\section{Data}

Rainfall data used in this study were obtained from the Agricultural Research Council (ARC) agroclimate database and the South African Weather Service (SAWS). Rainfall stations with 30 or more years of data with over $90 \%$ data efficiency (i.e. less than $10 \%$ missing daily values) were selected for the study. However, where the spatial network of stations is sparse (as in most parts of the Xhariep district), stations with
20 or more years of data with $90 \%$ data efficiency were used as complementary stations to aid in obtaining better interpolated surfaces. There were 309 stations that qualified to be used in this study (Fig. 1). Daily rainfall data from 1950 to 2008 was used in all the analyses of the rainfall season characteristics of the Free State Province. For analysis, the data was arranged in years starting from July to the following June, in order to make the entire summer rainfall season fall in one continuous dataset. All of the missing rainfall values at the selected stations were estimated by using the Inverse Distance Weighting Method shown in Eq. (1), which uses the first law of geography stating that 'Everything is related to everything else, but near things are more related to each other' (Longley et al., 2001 p. 61). The patching methodology employed a minimum of 2 neighbouring stations and a maximum of 5 stations within the radius of $50 \mathrm{~km}$; the estimated value at the target station is calculated giving more weight to the closest station value.

$$
y_{t}=\frac{\sum_{i=1}^{m} x_{t}^{i} / D_{i}^{2}}{\sum_{i=1}^{m} 1 / D_{i}^{2}}
$$

where:

$y_{t}$ is the estimated value of the missing data

$x_{t}^{i}$ is the value of the $i^{t^{\text {th }}}$ nearest weather station

$m$ ranges from 2 to 5

$D_{i}$ is the distance between the target station and the $i^{\text {th }}$ nearest weather station.

\section{Methods}

\section{Onset and cessation of rains and rainy season duration}

In this study the onset of rains is defined as the last day in which rainfall of $25 \mathrm{~mm}$ or above has been accumulated over the previous 10 days and at least $20 \mathrm{~mm}$ accumulated in the subsequent 20 days (Tadross et al., 2005; Hachigonta et al., 2008). This is the criterion commonly used to determine the beginning of the growing period in most semi-arid areas in southern Africa for dryland maize production (SADC-RRSU, 2004; FEWSNET, 2009). The additional $20 \mathrm{~mm}$ of cumulative rainfall over the next 2 dekads ensures that there is enough moisture, not only for germination but also to sustain the crop through the early development stage. The onset of rains was determined for all of the agricultural years at all 309 stations. The probability of onset failure was also determined by calculating the ratio of the number of years in which the onset criteria was not realised to the total number of agricultural years. As an example: if in 2 years out of the total of 20 years the onset of rains criterion was not realised then the probability would be $10 \%$. This probability indicates the chances of not being able to receive adequate rain to commence with planting. The end of the rainy season is obtained by searching for the last day on which the cumulative $25 \mathrm{~mm}$ over 10 days occurs. The length of the rainy season is calculated by subtracting the starting date of the rains in Julian days from 365 or 366 and adding the number of Julian days for end of the rains if the start of the season is before 31 December. If the start of rains is in January or later, the rainy season length is obtained by subtracting the start date of rains (in Julian days) from the end date.

The probability of a growing period of less than 50, 100, 120 or 140 days was also obtained for each station as the ratio of the number of years with rainy season duration of less than 
that particular duration to the total number of agricultural years. These probabilities are important for determining possible cultivars to be planted at a particular place. The probability at 50-days threshold represents the occurrences whereby the onset of rainfall enables the farmers to plant but the rainy season becomes too short for any maize cultivar to reach full maturity without any water stress. The 100-, 120- and 140-days thresholds relate to short-season, medium-season and longseason cultivars, respectively.

\section{Seasonal rainfall}

The rainfall season over the Free State is unimodal, mainly occurring in the summer months. The accumulated rainfall for the agricultural season was obtained by summing daily rainfall from 1 November to 31 March for each of the stations for all of the years.

\section{Statistical analysis}

The dates for the onset and cessation of rains, length of the growing season and seasonal rainfall were analysed for each station using Rainbow software, a package developed to determine frequency analysis and to test homogeneity of hydrometeorological data (Raes et al., 2006). The outliers (defined as points that are more than 1.5 times the inter-quartile range above the third quartile or below the first quartile (Von Storch and Zwiers, 1999)) were first removed from all of the datasets. Different probability levels (20\%, 50\% and 80\%) were determined for both non-exceedence and exceedence probability. The curve fitting was done using the maximum likelihood procedure, while the probabilities were estimated using the Weibull method (Raes et al., 2006). In this study, the Kolmogorov-Smirnov test and the closeness of linear relationship between the fitted line and data points were used to determine whether the rainy season characteristics data resemble the normal distribution for each station (Raes et al., 2006). The datasets for each rainy season index and climate station which do not conform to a normal distribution were transformed using 4 methods: a) square root, b) logarithmic, c) square method, and d) cube root method. The onset and duration of the rainy season are presented with the non-exceeding probability while the cessation of rains is presented using exceeding probability. The $20 \%$ probability level value for the onset implies that $20 \%$ of the values occur on or before that value. The $20 \%$ probability value for the duration of the rainy season means that $20 \%$ of the values are equal to, or less than, that value. For the cessation of rains, a $20 \%$ probability value implies that $20 \%$ of the values are on or later than that value. The $20 \%$ probability level denotes the seasonal rainfall accumulated during the dry seasons; $50 \%$ probability level is the median or average seasonal rainfall while the $80 \%$ level denotes the accumulated rainfall in relatively wet seasons.

\section{Mapping}

The interpolation of the rainy season characteristics was done using ArcGIS 9.3 software. The inverse distance weighting model imbedded in the spatial analyst tool was used for interpolating all of the indices. The maps for most of the rainy season indices are presented in dekads (10-day periods for the month) whereby the $1^{\text {st }}$ dekad is from the $1^{\text {st }}$ to $10^{\text {th }}$ day of the month, $2^{\text {nd }}$ dekad is from $11^{\text {th }}$ to $20^{\text {th }}$ day of the month and $3^{\text {rd }}$ dekad is from $21^{\text {st }}$ day to the end of the month.

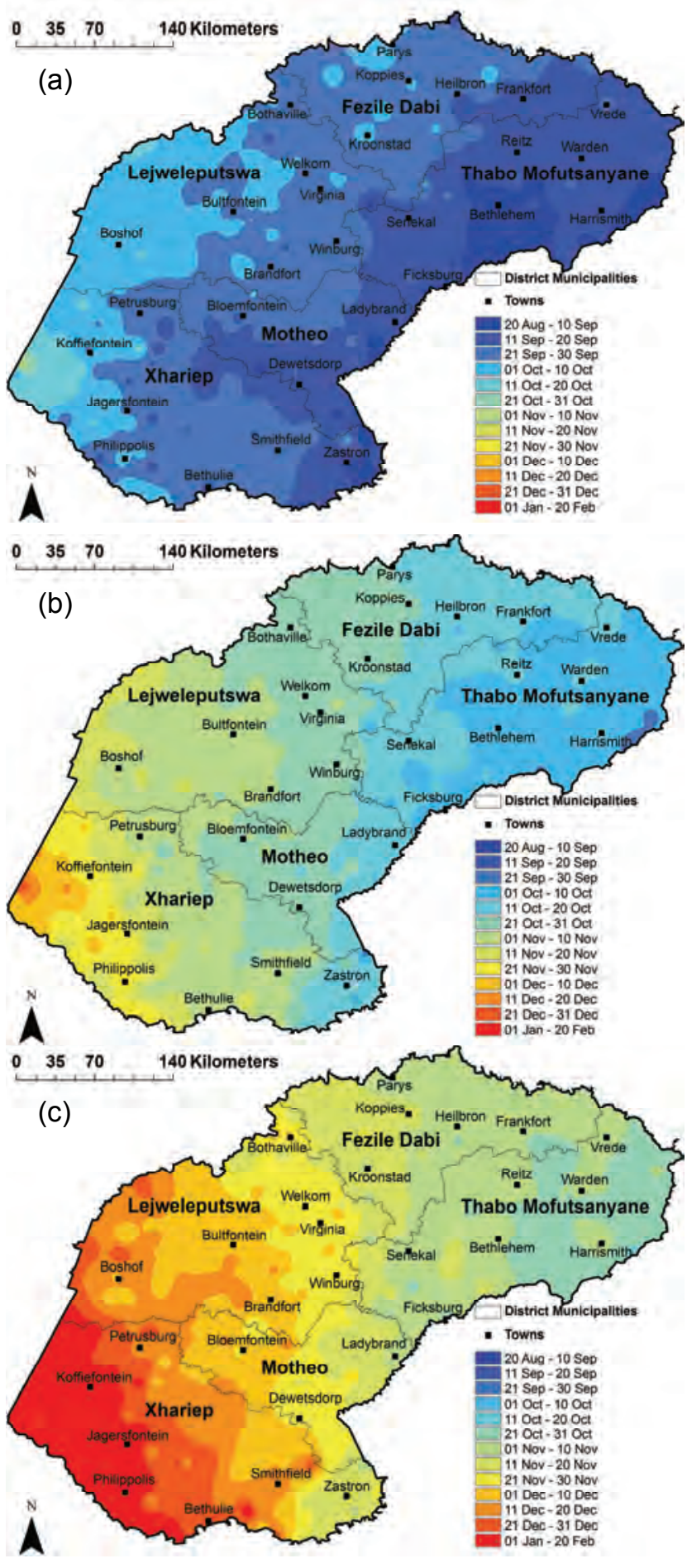

Figure 2

Date of onset of rainy season over the Free State Province at a) $20 \%$, b) $50 \%$ and c) $80 \%$ non-exceeding probabilities

\section{Results and discussion}

\section{Onset of rains}

Dates for the onset of rains at 20\%, 50\% and $80 \%$ non-exceeding probabilities are shown in Fig. 2. The whole of Thabo Mofutsanyane, most parts of Fezile Dabi, eastern Motheo and far eastern Xhariep districts experience their onset of rains at $20 \%(50 \%)[80 \%]$ on or before $2^{\text {nd }}$ dekad of September $\left(2^{\text {nd }}\right.$ dekad 
of October)[2 ${ }^{\text {nd }}$ dekad of November]. Western and southwestern Fezile Dabi, eastern Ljweleputswa and most parts of the Motheo district have onset of rains on or before $3^{\text {rd }}$ dekad of September( $3^{\text {rd }}$ dekad of October)[ $1^{\text {st }}$ dekad of December] at 20\%(50\%)[80\%] probability level. Central and western Lejweleputswa and most parts of the Xhariep district have their beginning of the rainy season on or before $1^{\text {st }}$ dekad of October( $1^{\text {st }}$ dekad of November) $\left[2^{\text {nd }}\right.$ dekad December $]$ corresponding to $20 \%(50 \%$ )[80\%] probability level. Farmers aiming at planting maize for early markets can utilise earliest onset of rains occurring in September or October depending on the locality of the farm. But it should be emphasized that the chances of experiencing false start of the season at the period corresponding to the $20 \%$ probability are high (80\%); hence crops might not have enough soil water to sustain them during the early stages of vegetative growth. The $50 \%$ non-exceedence probability level is that which is most used by the farmers, as there is a 50:50 chance of the onsets being significant enough to support a maize crop at the early vegetative stage. Utilisation of this probability level for farmers aiming at producing green mielies to be sold earlier than normal in agricultural markets is recommended in preference to the $20 \%$ probability, unless there are supplementary irrigation facilities available. The $80 \%$ probability level is associated with low risk of crop failure during the early stages of growth and development. But farmers are encouraged to plant short-season maize varieties, especially in areas of low heat units accumulation (highlands), to avoid the plant growing period being aligned to periods of high agroclimatic risk (Moeletsi, 2010). Low-lying areas in most parts of the province are not associated with high agroclimatic hazards, especially frost, which has a detrimental effect of productivity.

\section{Probability of onset failure}

Assessment of the number of years in which the onset criterion is not met is an important risk index. Over the Free State Province, the chances of onset failure are zero over most parts of the Thabo Mofutsanyane district (Fig. 3). This means that the onset criteria (over $25 \mathrm{~mm}$ accumulated in the previous 10 days and over $20 \mathrm{~mm}$ in the following 20 days) is realised at all seasons in these places, making them less vulnerable to crop failure due to inadequate rains to support land preparation and planting (Moeletsi, 2010). The other places with no chance of onset failure are patches over south-eastern Xhariep, eastern Motheo and western Fezile Dabi, and pockets over eastern and western Lejweleputswa (Fig. 3). Most parts of the province have a less than $2 \%$ chance of onset failure, implying very low risk of not receiving significant rains to initiate planting activities. The Xhariep district has a relatively high risk of onset failure especially over the southern and western parts where the ratio of agricultural seasons with 'no onset date' over the total number of agricultural seasons is up to 0.1 . A $10 \%$ chance of not obtaining significant rains to start soil preparation and planting implies relatively high risk of crop failure due to false onsets, because at times the rainfall received does not stretch to the early vegetative stages.

\section{Cessation of rains}

Cessation or retreat of rain dates for the $20 \%, 50 \%$ and $80 \%$ exceeding probability, representing return periods of 5 years, 2 years and 4 in 5 years, respectively, are shown in Fig. 4 . As compared with the onset of rains in the previous sub-section, cessation of rain dates shows less spatial variation. At the
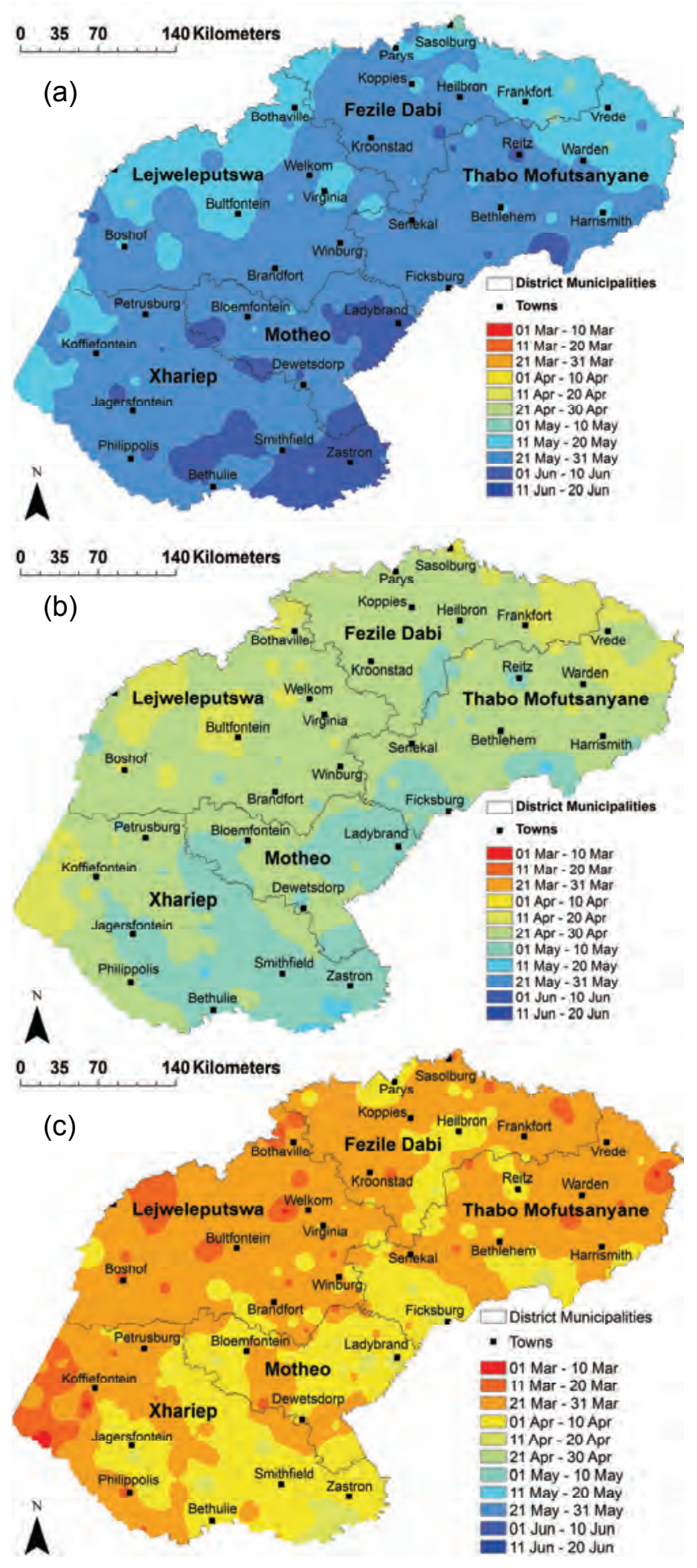

Figure 3

Date of cessation of rainy season over the Free State Province at a) $20 \%$, b) $50 \%$ and c) $80 \%$ exceeding probabilities

20\%(50\%)[80\%] probability level, most parts of the Free State Province have the cessation of rains occurring on or after the $2^{\text {nd }}$ dekad of May( $3^{\text {rd }}$ dekad of april)[ $3^{\text {rd }}$ dekad of March]. Small pockets over the eastern Free State, western Xhariep and Lejweleputswa have earlier cessation dates by 1 dekad at all probability levels. In contrast, some parts of Motheo, most of central Xhariep and some patches in the Thabo Mofutsanyane district have their cessation of rains later by 1 dekad at all of 


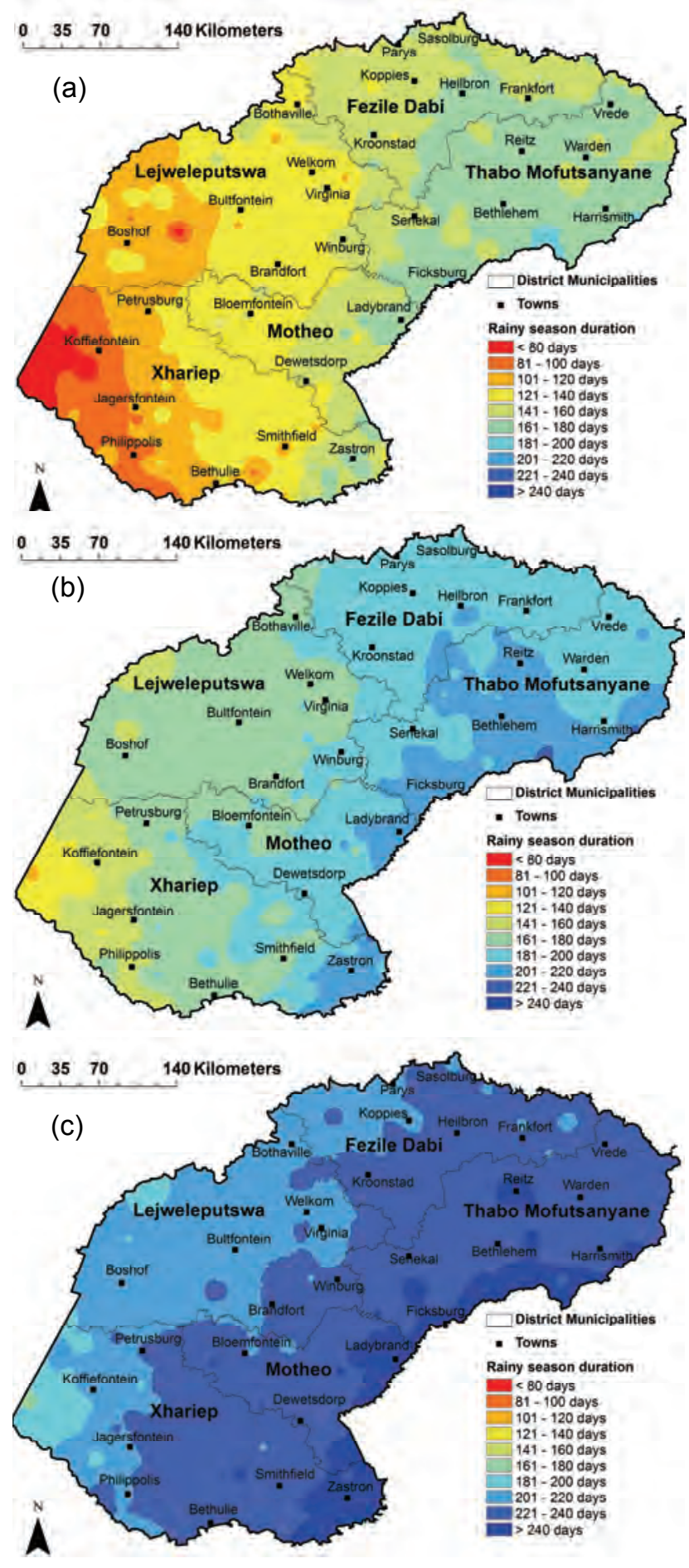

Figure 4

Rainy season duration over the Free State Province at a) $20 \%$, b) $50 \%$ and c) $80 \%$ non-exceeding probabilities

the probability levels. Coinciding the time of maturity of the maize crop with the $20 \%$ probability of the cessation of the rainy season can potentially subject the crop to high risk of water stress because at this probability level the chances of end of rains being earlier are high (80\%). At that risk level, frost incidences are also high in some places in the province thus increasing chances of crop failure and poor grain quality. If the planting of maize is planned in a way that the

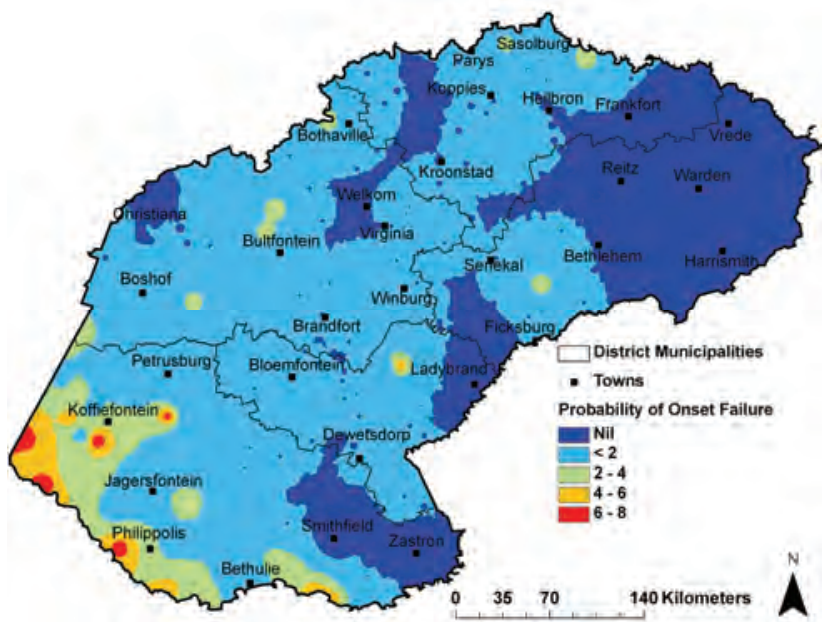

Figure 5

Probability of rain onset failure over the Free State Province

maturity coincides with these $80 \%$ probability last rain dates, the loss due to lack of water to support the maize crop can be minimised.

\section{Duration of rainy season}

Duration of the rainy season for the $20 \%, 50 \%$ and $80 \%$ nonexceeding probabilities over the Free State Province are shown in Fig. 5. Thabo Mufutsanyane district has the longest rainy season duration mainly due to early onset of rains experienced in the area. The 20\%(50\%)[80\%] percentile values in this district mostly range from 161 to 180 days(181-220 days) [over 220 days]. In the Fezile Dabi district rainy season duration in most places is between 141 and 160 days(181-200 days) [221-240 days] at 20\%(50\%)[80\%] probability level. Over the remainder of the province (Lejweleputswa, Motheo and Xhariep districts), duration of the rainfall season ranges from less than 80 days $(<140$ days) $[<200$ days] over the western parts and increases eastwards to values up to 160 days(220 days) [240 days] in the eastern and south-eastern parts at 20\%(50\%) [80\%] risk levels. Planting of medium- to long-season maize varieties in places where rainy season is less than 120 days can result in excessive water stress conditions because the later stages of the growing period of the crop (growth stages with high water requirements) would be subjected to insignificant rains. Depending on the actual planting date, median duration of rainy season can fully support the growing period of most maize varieties in most parts of the Free State, except over the western parts where short periods are experienced.

\section{Probability of rainy season of less than 50, 100, 120 and 140 days}

The absolute probabilities of having a rainy season of less than 50, 100, 120 and 140 days are shown in Fig. 6. In this study, rainy season duration of 100, 120 and 140 days denotes duration of short-season variety, medium-season, and medium-late to long-season maize varieties, respectively. But it has to be noted that the actual duration of the variety is highly dependent on the heat unit requirement from emergence to maturity (Neog et al., 2008). Due to varying heat unit accumulation rates over the Free State, one variety can take 100 days to mature 

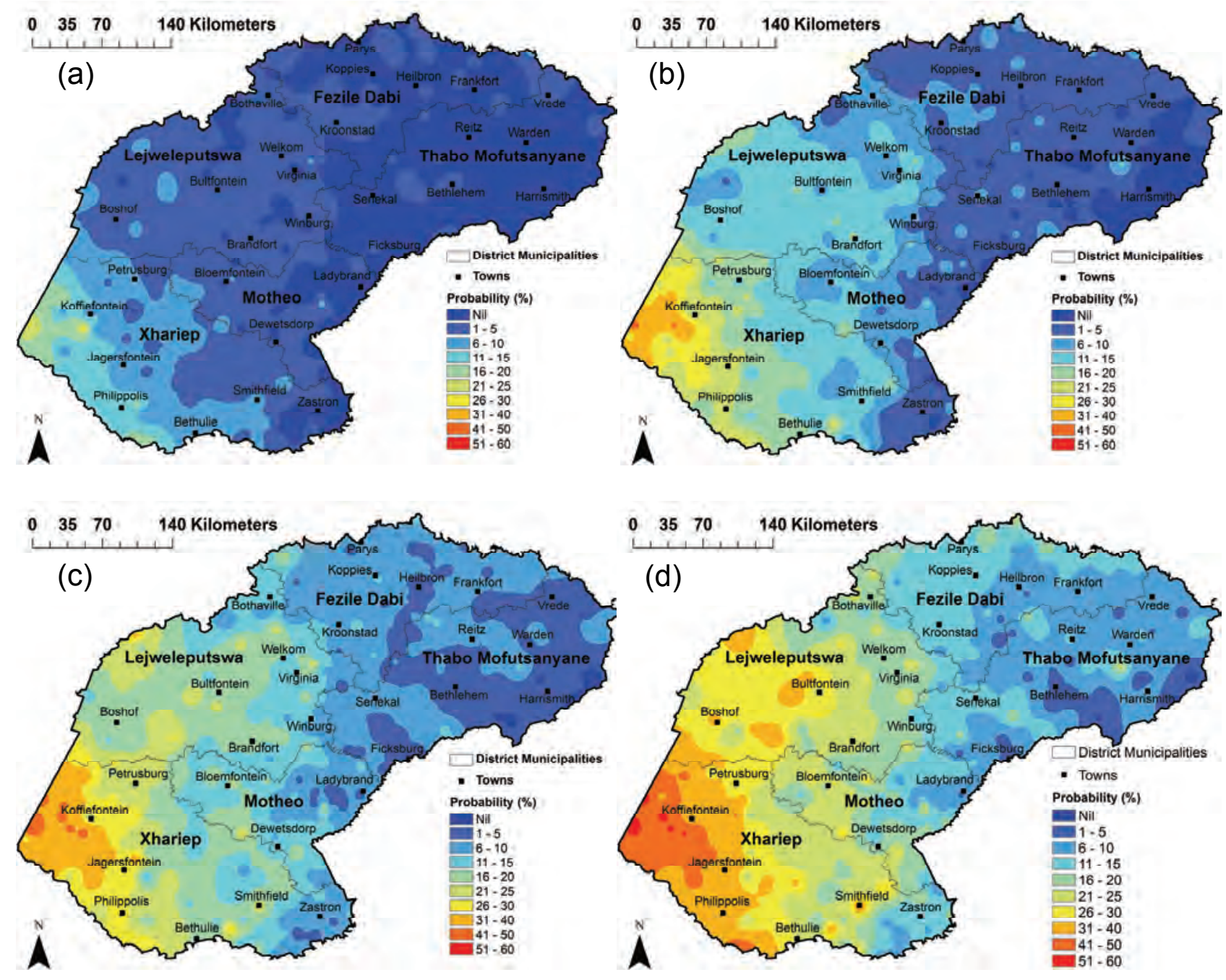

Figure 6

Probability of rainy season over the Free State Province of less than a) 50 days, (b) 100 days, (c) 120 days and (d) 140 days

over the western parts and over 140 days to mature over the eastern parts of the province, depending on the planting date (Pannar, 2010).

The probability of obtaining a rainy season of less than 50 days is less than $6 \%$ for the Fezile Dabi, Lejweleputswa, Motheo, far eastern Xhariep and Thabo Mofutsanyane districts, with the eastern parts of the Thabo Mofutsanyane district having zero chance (Fig. 6a). The risk increases when moving south-westwards, reaching a maximum of $30 \%$ over the western parts (west of Koffiefontein). These areas of high risk cannot be used for maize crop farming unless under irrigation. The chances of the rainy season being less than 100 days, as shown in Fig. 6b, are low over the Fezile Dabi, Thabo Mofutsanyane and eastern parts of the Motheo district, with less than $6 \%$ probability. In these areas, planting of shortseason maize varieties ( $<100$ days) is subjected to low risk of failure due to inadequate rainfall to support plant growth and development. As for the Lejweleputswa district, the risk is slightly higher for most places with probability values between 11 and 20\%. The highest chances of a rainy season of less than 100 days are over the Xhariep district especially in the west where probability values of up to $40 \%$ are realised. The lowest risk of planting a 100-day maize crop in this district is obtained over the southeast (east of Smithfield), with probability of less than $10 \%$, while the central parts experience relatively moderate risk of between 11 and $20 \%$.

The probability of rainy season duration of less than 120 days (growing period of short- to medium-season maize cultivar) is less than $6 \%$ for most parts of the central and eastern Thabo Mofutsanyane district and patches over the Fezile Dabi district (Fig. 6c). Low probability indicates that 120-day maize cultivar growth and development in these areas would not be hampered by a short rainy season period. Most parts of Fezile Dabi have between 6 and 10\% probability of a rainy season of less than 120 days. Less than $10 \%$ probability shows high suitability of planting a short- to medium-season maize crop. Most areas over the Lejweleputswa and Motheo districts have probability values between 11 and $20 \%$. The western parts of the former have relatively high risk with patches of 21 to $30 \%$ values, while over the north and eastern Lejweleputswa there are pockets of less than $11 \%$. Over the Xhariep district, the area around Zastron has relatively low values while for the western parts risk is higher, with up to $50 \%$ probability of a rainy season of less than 120 days.

The risk of obtaining less than 140 rainy season duration days (growing period for medium- to long-season maize 

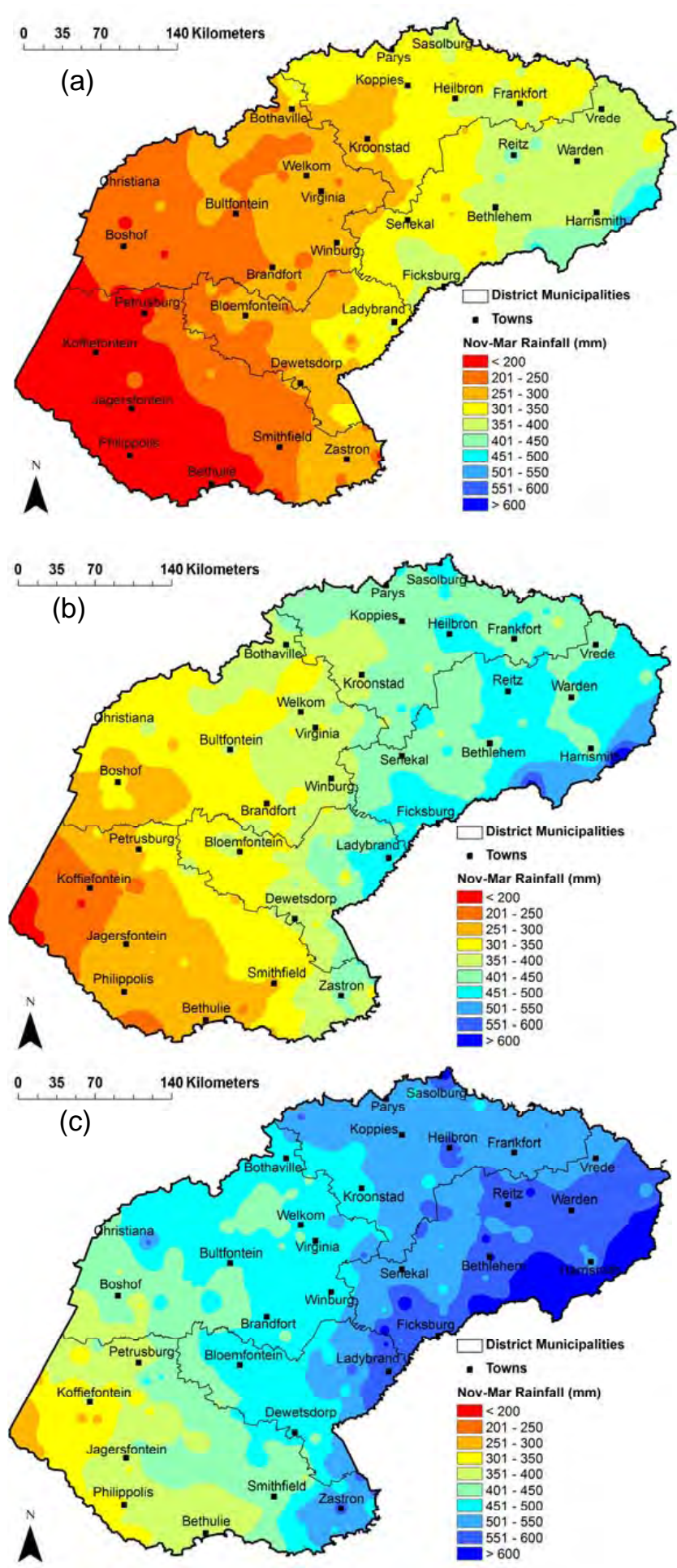

Figure 7

Seasonal rainfall (November to March) amount over the Free State at a) 20\%, b) 50\% and c) $80 \%$ non-exceeding probabilities

cultivar) is low over the Thabo Mofutsanyane district with less than $6 \%$ probability (Fig. 6d). Most parts of this district record between 6 and 10\% chances of rainy season length of less than 140 days. Over most parts of the Fezile Dabi district the risk is lower than $20 \%$ in all of the places, while in Lejweleputswa most parts have a risk of between 21 and 30\%. The area extending from Bothaville to Brandfort in the Lejweleputswa district has a probability ranging from 11 to $20 \%$. In the Motheo and
Xhariep districts the risk is low over the eastern parts, increasing towards the west with the highest risk of up to $60 \%$ over western Xhariep. High probability at the 140-days threshold shows unsuitability for planting medium- to long-season maize varieties.

\section{Seasonal rainfall}

Seasonal rainfall varies a lot over the Free State Province, with a clear north-eastward gradient, and with the lowest values of less than $200 \mathrm{~mm}(<250 \mathrm{~mm})[<350 \mathrm{~mm}]$ accumulated rainfall from November to March being over the western and southwestern parts at 20\%(50\%)[80\%] probability level (Fig. 7). Seasonal rainfall values over the central, south-eastern and northern parts of the province mostly range between 251 and $350 \mathrm{~mm}(351-450 \mathrm{~mm})[451-550 \mathrm{~mm}$ ] at 20\%(50\%)[80\%] percentiles. Areas of highest seasonal rainfall are evident over the far eastern Free State with values exceeding $400 \mathrm{~mm}(500 \mathrm{~mm})$ [600 mm] at the three risk levels. These areas stand a better chance of high maize production because maize water requirements are likely to be satisfied even in the driest $(20 \%$ probability) seasons. Places of less than $400 \mathrm{~mm}$ in the median category are likely to have soil water deficits impacting negatively on maize production, and thus the use of high water-use efficiency cultivars will be advisable for these areas.

\section{Conclusions and recommendations}

The onset-of-rains results clearly show that, for Thabo Mofutsanyane, eastern parts of Fezile Dabi, far eastern parts of Motheo and far eastern parts of Xhariep districts, planting can be done early with onset occurring on or before the second dekad of November in 4 out of 5 years. The cessation of rains in these places is also relatively late. For the western parts of Fezile Dabi, eastern parts of Xhariep and most parts of Motheo and Lejweleputswa, the onset of rains is not as early as the above regions. The duration of the rainy season over the Free State varies significantly for all the probability levels owing to great variation in the onset of rains. By contrast, the province has low spatial variation of dates of cessation of rains. The spatial variation of the $20 \%, 50 \%$ and $80 \%$ probability levels is more or less similar. Generally, the rainy season duration for all of the probability levels is short over the south-western Free State (west of Koffiefontein) and increases gradually moving eastwards or north-eastwards and peaking over the southeastern, eastern and far north-eastern parts of the province. In most places the $20^{\text {th }}, 50^{\text {th }}$ and $80^{\text {th }}$ percentile duration of the rainy season is over 120, 140 and 200 days, respectively. At $20 \%$ probability, the risk of total failure of maize is high over Xhariep and the western parts of the Lejweleputswa district, especially for the medium- and long-season cultivars. The risk at other parts of the province is relatively low. At 50\% probability, the risk of crop failure due to water stress is high for long-season maize cultivars over the far western parts of the Xhariep district. At $80 \%$ probability, the risk for crop failure caused by water shortages over the Free State is minimal due to very long growing periods, especially over the central, northern and eastern parts of the province.

Seasonal rainfall is lowest over the south-western parts of the Free State. In these regions accumulated rainfall is less than $350 \mathrm{~mm}$, even in very wet seasons (80\% non-exceedence probability). These areas are not suitable for rain-fed maize production. The central and western parts obtain moderate seasonal rainfall with median rainfall between 300 and 400 
mm. Highest accumulated rainfall from November to March is recorded mostly in the northern and eastern parts of the province with median rainfall exceeding $400 \mathrm{~mm}$. These places are expected to have a relatively low risk of crop failure due to crop water deficiency.

The results of the analysis for all of the indices show high vulnerability of maize production over the western, southern and south-western parts of the Free State Province. The rainy season is favourable for all maize cultivars over the Thabo Mofutsanyane district due to early onset of rain resulting in a long rainy season and high seasonal rainfall especially in the north-eastern parts. The northern parts (Fezile Dabi district) also show a relatively long rainy season as well as less risk of onset failure. It is thus expected that maize should flourish in those areas of low risk if all other climatic requirements are met and rainfall is the only limiting factor to maize production. The western Xhariep district and some pockets over western Lejweleputswa have the highest risk of onset failure and probabilities of rainy season being less than 100, 120 and 140 days. Planting of maize of any cultivar length is not advisable under dryland conditions in these areas.

\section{Acknowledgements}

The authors are grateful to the Agricultural Research Council Institute for Soil, Climate and Water which provided financial support for the research (Project no. 57/007). Mr Seboko Moopisa is thanked for assisting in writing the rainfall patching program.

\section{References}

ATI OF, STIGTER CJ and OLADIPO EO (2002) A comparison of methods to determine the onset of the growing season in northern Nigeria. Int. J. Climatol. 23 731-742.

CAMBERLIN P and DIOP M (2003) Application of daily rainfall principal component analysis to the assessment of the rainy season characteristics in Senegal. Climate Res. 23 159-169.

DAFF (DEPARTMENT OF AGRICULTURE, FORESTRY AND FISHERIES, SOUTH AFRICA) (2010) Abstract of Agricultural Statistics, 2010. National Department of Agriculture, Forestry and Fisheries, Pretoria, South Africa. URL: www.nda.agric.za/docs/ statsinfo/Abstract2010.doc (Accessed 10 December 2010). 145 pp.

DAVIS J, TAVASCI D and MARAIS L (2006) Fostering Rural and Local Economic Development in the Free State of South Africa. Natural Resources Institute, University of Greenwich, UK. 2-10.

DE JAGER JM, POTGIETER AB and VAN DEN BERG WJ (1998) Framework for forecasting the extent and severity of drought in maize in the Free State Province of South Africa. Agric. Syst. 57 (3) 351-365

FEWSNET (FAMINE EARLY WARNING SYSTEM NETWORK) (2009) Southern Africa Food Security Update - November 2009. URL: http://www.reliefweb.int/rw/RWFiles2009.nsf/ FilesByRWDocUnidFilename/SODA-7YDSVB-full_report. pdf/\$File/full report.pdf (Accessed 10 January 2010). 11 pp.

FSP (FREE STATE PROVINCE) (2005) Free State Province Provincial Growth and Development Strategy (PGDS) 2005 - 2014. Free State Provincial Government, Bloemfontein, South Africa. $18 \mathrm{pp}$.

HACHIGONTA S, REASON CJC, and TADROSS M (2008) An analysis of onset date and rainy season duration over Zambia. Theor. Appl. Climatol. 91 229-243.
LONGLEY PA, GOODCHILD MF, MAGUIRE DJ and RHIND DW (2001) Geographic Information Systems and Science. Wiley, New York. 296-297.

MOELETSI ME (2010) Agroclimatological risk assessment of rain-fed maize production for the Free State Province of South Africa. PhD thesis. Department of Soil, Crop and Climate Sciences, University of the Free State. $232 \mathrm{pp}$.

MOELETSI ME, MELLAART EAR and MPANDELI NS (2011a) Crop water requirements analysis for maize trial sites in Makhado during 2007/08 season. In: Attri SD, Rathore LS, Sivakumar MVK and Dash SK (eds.) Challenges and Opportunities in Agrometeorology. Springer, Berlin. 485-490.

MOELETSI ME, WALKER S and LANDMAN WA (2011b) ENSO and implications on rainfall characteristics with reference to maize production in the Free State Province of South Africa. Phys. Chem. Earth 36 715-726.

MUGULAVAI ED, KIPKORIR EC, RAES D and RAO MS (2008) Analysis of rainfall onset, cessation and length of growing season for western Kenya. Agric. For. Meteorol. 148 1123-1135.

MWALE D, GAN TY and SHEN SSP (2004) A new analysis of and predictability of seasonal rainfall of Central Southern Africa for 1950-94. Int. J. Climatol. 24 1509-1530.

NEOG P, BHUYAN J and BARUAH N (2008) Thermal indices in relation to crop phenology and seed yield of soybean (Glycine max L. Merrill). J. Agrometeorol. (special issue - part 2) 300-392.

PANNAR (2010) 2010 Product Catalogue. PANNAR SEED, PO Box 19, Greytown 3250, South Africa. 27 pp.

RAES D, SITHOLE A, MAKARAU A and MILLFORD J (2004) Evaluation of first planting dates recommended by criteria currently used in Zimbabwe. Agric. For. Meteorol. 125 177-185.

RAES D, WILLIAMS G and GBAGUIDI F (2006) RAINBOW: a software package for analysing climatological/hydrologic data frequency analysis-Test of homogeneity. Department of Land Management, Faculty of Agricultural and Applied Biological Sciences, K.U., Leuven, Belgium. URL: http://www.iupware.be (Accessed 21 February 2007).

REASON CJC, HACHIGONTA S and PHALADI RF (2005) Interannual variability in rainy season characteristics over the Limpopo region of Southern Africa. Int. J. Climatol. 25 1835-1853.

SADC-RRSU (SOUTHERN AFRICAN DEVELOPMENT COMMUNITY - REGIONAL REMOTE SENSING UNIT) (2004) Special Agromet- Update: Follow-up analysis of drought situation in Southern Africa 2003/2004 crop growing season. SADC-RRSU, Gaborone, Botswana. 4 pp.

SIVAKUMAR MVK (1990) Exploiting rainy season potential from the onset of rain in the Sahelian zone of West Africa. Agric. For. Meteorol. 51 (3-4) 321-332.

TADROSS MA, HEWITSON BC and USMAN MT (2005) The interannual variability of the onset of the maize growing season over South Africa and Zimbabwe. J. Clim. 18 3356-3372.

TSHEKO R (2003) Rainfall reliability, drought and flood vulnerability in Botswana. Water SA 29 (4) 389-392.

TVEITO OE, BJØRDAL I, SKJELVÅG AO and AUNE B (2005) A GIS-based agro-ecological decision system based on gridded climatology. Meteorol. Appl. 12 57-68.

UNGANAI LS (1994) Drought and Southern Africa: A note from the Harare Regional Drought Monitoring Centre. URL: www.drought. unl.edu/pubs/dnn/arch18.pdf (Accessed 7 May 2010).

USMAN MT and REASON CJC (2004) Dry spell frequencies and their variability over Southern Africa. Climate Res. 26 199-201.

VOGEL CH and DRUMMOND JH (1993) Dimensions of drought: South African case studies. GeoJournal 30 (1) 93-98.

VON STORCH H and ZWIERS FW (1999) Statistical Analysis in Climate Research. Cambridge University Press, Cambridge. 